Received 23 March 2018, Accepted 21 May 2018

Link to DOI:

10.25520/WNJ.V02.i1.0002

Journal Website:

www.worldnutrijournal.org

\section{Comparing the Efficacy of Ketogenic Diet with Low Fat Diet for Weight Loss in Obesity Patients: Evidence-Based Case Report}

\author{
Nurul R.M. Manikam ${ }^{1}$, Nico I. Pantoro ${ }^{2}$, Karina Komala ${ }^{1}$, Ayu Diandra Sari ${ }^{1}$

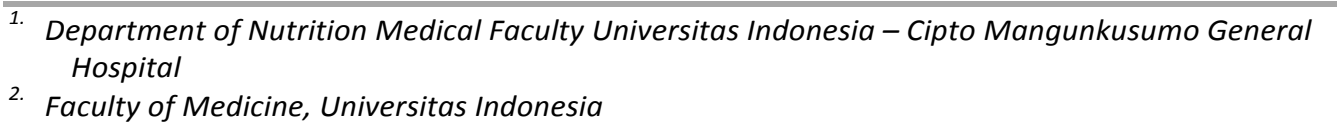

\begin{abstract}
Introduction Obesity is a nutritional disease which is still a health burden particularly in Jakarta. The main treatment for obesity is nutritional intervention. Nowadays, several dietary approaches have been developed, including ketogenic diet, which is still controversial. Methods Literature search had been done within 4 databases including PubMed ${ }^{\circledR}$, Cochrane $^{\circledR}$, Google $^{\circledR}$ Scholar, and Science Direct ${ }^{\circledast}$, using keywords: obesity, ketogenic diet, low-fat diet, and weight loss. Then, Medical Sub Heading (MeSH) was used. The search resulted in two articles which were appraised according to aspects of validity, importance, and applicability Results A randomized-controlled trial study showed similar effect of weight loss with ketogenic diet compared to low-fat diet. On the other hand, a meta-analysis study showed ketogenic diet caused more weight loss than lowfat diet. Both studies showed an increased risk of cardiovascular disease from the ketogenic diet group, which were shown by a decrease of flow-mediated dilatation and an increase of LDL-C. Conclusion Ketogenic diet shows a better long-term effect for weight loss in obese patients than low-fat diet. However, ketogenic diet may increase the cardiovascular event risk significantly.

Keywords ketogenic diet, low-fat diet, obesity, weight loss
\end{abstract}

\section{Introduction}

Obesity and overweight, also known as malnutrition, are diseases in nutrition and the metabolic field. These define as conditions in which a patient has an above normal body mass index (BMI). ${ }^{1}$ In Indonesia, BMI values are referred from the Asia-Pacific World Health Organization guidelines, with the normal range of $18.5-22.9 \mathrm{~kg} / \mathrm{m}^{2}$. Overweight and obesity are

\begin{tabular}{l}
\hline Corresponding author: \\
Nurul R.M. Manikam \\
Department of Nutrition Medical Faculty of \\
Medicine,Universitas Indonesia \\
Emailaddress : nurul.ratna@,hotmail.com \\
\hline
\end{tabular}

defined as body mass index of $23-24.9 \mathrm{~kg} / \mathrm{m}^{2}$ and $>25 \mathrm{~kg} / \mathrm{m}^{2}$, respectively. ${ }^{2}$ Obesity is an important issue due to its high prevalence. According to Riset Kesehatan Dasar (Riskesdas) Indonesia in year 2013 , the prevalence of obesity in Jakarta is 30\% in men and $40 \%$ in women. ${ }^{3}$ In addition, obesity is a major risk factor of chronic degenerative diseases, such as diabetes mellitus, dyslipidemia, and hypertension. ${ }^{4}$

The etiology is mostly due to poor eating behavior, thus patient management focuses mainly in nutritional intervention. The nutritional intervention widely used is calories restriction using low-fat diet. ${ }^{5,6}$ However, this nutritional intervention often causes lack of obedience of the patients. ${ }^{5}$ 
In order to overcome the problem, several nutritional interventions had been suggested using various macronutrient compositions. Among them is ketogenic diet, which defines as dietary pattern with high-fat and very-low-carbohydrates compositions for daily intake. ${ }^{7,8}$ The goal of ketogenic diet is to increase ketogenesis, which happens when the body is lack of adequate energy from carbohydrate, particularly the central nervous system. $^{7}$

Ketogenic diet remains controversial in our population. It can cause weight loss however the long-term effect on body weight and the adverse effects are still unknown. ${ }^{7}$ In addition, the effect of weight loss from ketogenic diet compared to other diets is still controversial. ${ }^{7,8}$ Therefore, this paper focuses on evidence-based critical review about comparing the efficacy of ketogenic diet with lowfat diet for weight loss in obese patients.

\section{Case Illustration}

Male, 46 years old, visited clinic for health consultation. He said during exercise, there was cholesterol check-up and his cholesterol level was $252 \mathrm{mg} / \mathrm{dL}$. The patient was concerned about his condition which could cause health complications in the future. He has family history of cardiovascular disease: his older brother had heart attack 3 months ago and his father had stroke. The patient also complained about his excessive body weight. Antrophometric measurement showed body height of $158 \mathrm{~cm}$ and body weight of $82 \mathrm{~kg}$. Thus, the BMI is $32.4 \mathrm{~kg} / \mathrm{m}^{2}$ (grade II obesity). Other physical examinations showed normal results. Therefore, he was suggested to have a lifestyle change (especially in his dietary pattern). He heard from his friends that ketogenic diet could reduce weight faster than other diets. Therefore, patient came to clinic to consult the doctor about ketogenic diet or the appropriate dietary pattern for his health.

"In obese patients, is ketogenic diet intervention better than low-fat diet for weight loss?" Table 1 shows clinical questions formula.
Table 1. Clinical questions formula

\begin{tabular}{llll}
\hline $\begin{array}{c}\text { Patient/ } \\
\text { Problem } \\
(\mathbf{P})\end{array}$ & $\begin{array}{l}\text { Intervention } \\
\text { (I) }\end{array}$ & $\begin{array}{c}\text { Comparison } \\
\text { (C) }\end{array}$ & $\begin{array}{c}\text { Outcome } \\
\text { (O) }\end{array}$ \\
\hline $\begin{array}{l}\text { Obese } \\
\text { patients }\end{array}$ & $\begin{array}{l}\text { Ketogenic } \\
\text { diet }\end{array}$ & Low-fat diet & $\begin{array}{l}\text { Weight } \\
\text { loss }\end{array}$ \\
\hline $\begin{array}{l}\text { Clinical } \\
\text { Question } \\
\text { Type }\end{array}$ & Treatment & \\
\hline $\begin{array}{l}\text { Study } \\
\text { Design }\end{array}$ & $\begin{array}{l}\text { Randomized-controlled trials (RCTs) or } \\
\text { meta-analysis or systematic review of }\end{array}$ \\
\hline & RCTs & \\
\hline
\end{tabular}

\section{Methods}

Literature search had been done within 4 databases: PubMed $\AA$, Cochrane $\AA$, Google ${ }^{\circledR}$ Scholar, and Science Direct ${ }^{\circledR}$ by using the keywords obesity, ketogenic diet, low-fat diet, and weight loss. Afterwards, Medical Sub Heading (MeSH) was used. Table 2 shows the strategies for articles search.

The total number of articles found based on keywords was 168 articles. Inclusion criteria for title selection and abstract were researches in patients with overweight or obesity; with randomized controlled trials (RCTs), meta-analysis or systematic review of RCTs as study designs; and available in free English full-text. Ten articles in which titles and abstracts matched with the inclusion criteria were found. Then, duplication equality screening was done, which resulted in remaining 4 articles. Reviews were performed on the 4 full-text articles. Among them, two articles were relevant to the clinical questions. Oneof them was an individual RCT while the other was a metaanalysis of RCTs. Figure 1 shows flow chart of the method used for article searches and selections.

Critical reviews were performed on selected articles using the criterias from Oxford Center for Evidence Based Medicine 2011 including the aspects of validity, importance, and applicability. 
Table 2. The strategies for article search

\begin{tabular}{|c|c|c|c|c|}
\hline No & Database & Keywords & Findings & Selected \\
\hline 1. & PubMed $\mathbb{R}$ & $\begin{array}{l}\text { Ketogenic Diet }[\mathrm{MeSH}] \text { OR Diet, Carbohydrate-restricted } \\
{[\mathrm{MeSH}] \text { ANDDiet, Fat-Restricted [MeSH] }} \\
\text { ANDObesity [MeSH] OR Overweight }[\mathrm{MeSH}] \\
\text { ANDWeight Loss }[\mathrm{MeSH}]\end{array}$ & 79 & 6 \\
\hline 2. & Cochrane ${ }^{\circledR}$ & $\begin{array}{l}\text { Ketogenic Diet }[\mathrm{MeSH}] \text { OR Diet, Carbohydrate-restricted } \\
{[\mathrm{MeSH}] \text { ANDDiet, Fat-Restricted [MeSH] }} \\
\text { ANDObesity [MeSH] OR Overweight }[\mathrm{MeSH}] \\
\text { ANDWeight Loss }[\mathrm{MeSH}]\end{array}$ & 52 & 4 \\
\hline 3. & $\begin{array}{l}\text { Google }{ }^{\circledR} \\
\text { Scholar }\end{array}$ & $\begin{array}{l}\text { Ketogenic Diet }[\mathrm{MeSH}] \text { OR Diet, Carbohydrate-restricted } \\
{[\mathrm{MeSH}] \text { ANDDiet, Fat-Restricted }[\mathrm{MeSH}]} \\
\text { ANDObesity }[\mathrm{MeSH}] \text { OR Overweight }[\mathrm{MeSH}] \\
\text { ANDWeight Loss }[\mathrm{MeSH}]\end{array}$ & 17 & 0 \\
\hline 4 & $\begin{array}{l}\text { Science } \\
\text { Direct } \AA\end{array}$ & $\begin{array}{l}\text { Ketogenic Diet }[\mathrm{MeSH}] \text { OR Diet, Carbohydrate-restricted } \\
{[\mathrm{MeSH}] \text { ANDDiet, Fat-Restricted }[\mathrm{MeSH}]} \\
\text { ANDObesity }[\mathrm{MeSH}] \text { OR Overweight }[\mathrm{MeSH}] \\
\text { ANDWeight Loss }[\mathrm{MeSH}]\end{array}$ & 20 & 0 \\
\hline
\end{tabular}

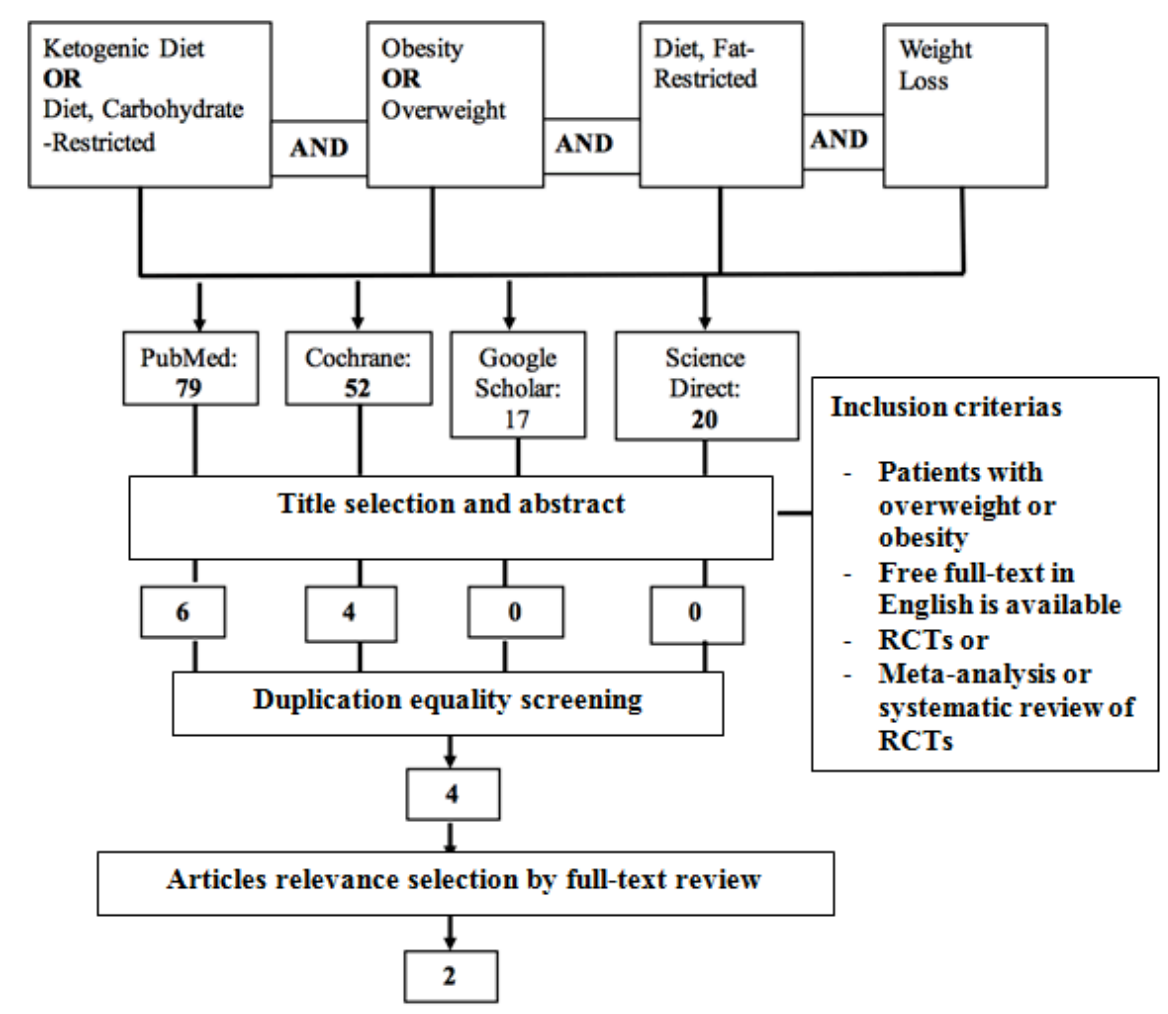

Figure 1. Flow chart of the methods used for article search and selection 


\section{Results}

\section{Validity}

Table 3 shows the critical appraisal on the validity of the study by Wycherley TP et al. ${ }^{9}$

Table 3. Critical appraisal on the validity of study

\begin{tabular}{|c|c|}
\hline Parameter of validity & Wycherley TP et al $(2010)^{9}$ \\
\hline Title & $\begin{array}{l}\text { Long-term effects of weight loss with a very-low-carbohydrate and low-fat diet on } \\
\text { vascular function in overweight and obese patients }\end{array}$ \\
\hline Subjects & $\begin{array}{l}\text { The total study subjects were } 118 \text { patients, consisted of } 57 \text { patient with low } \\
\text { carbohydrate high fat diet }(61 \%) \text { and } 61 \text { patients receiving low fat diet with equally } \\
\text { calculated calories. At the end of the study, only } 49 \text { patients finished the whole } \\
\text { study, i.e subjects in the intervention group and } 23 \text { in the control group. }\end{array}$ \\
\hline Randomization & $\begin{array}{l}\text { Yes, randomization was done on patients who received both ketogenic and low-fat } \\
\text { diets. }\end{array}$ \\
\hline $\begin{array}{l}\text { Randomization blinding } \\
\text { (allocation concealment) }\end{array}$ & $\begin{array}{l}\text { Yes, blinding technique was used by the investigators in this study, but could not be } \\
\text { applied to the study subjects. }\end{array}$ \\
\hline $\begin{array}{l}\text { Initial characteristics of } \\
\text { the subjects/ objects }\end{array}$ & $\begin{array}{l}\text { Yes, both groups of patients have similar demographic characteristics in terms of } \\
\text { age, sex, body mass index, blood pressure and cardiovascular risk profile. }\end{array}$ \\
\hline Equal treatment & Yes, both groups were equally treated. \\
\hline Adequate follow up & $\begin{array}{l}\text { Yes, both groups underwent a follow-up and nutritional consultation in week- } 8 \text { and } \\
\text { every month afterwards. Data was obtained in the beginning of the study and after } 52 \\
\text { weeks. }\end{array}$ \\
\hline $\begin{array}{l}\text { Intention-to-treat } \\
\text { analyses }\end{array}$ & No, data analysis in this study utilized a per-protocol analysis \\
\hline Level of Evidence & 2 (Individual RCT) \\
\hline
\end{tabular}

Table 4 shows critical appraisal on the validity of

Bueno NB et al ${ }^{10}$ study.

Table 4. Critical appraisal on the validity aspect of meta-analysis

\begin{tabular}{ll}
\hline $\begin{array}{l}\text { Parameter } \\
\text { Validity }\end{array}$ & \multicolumn{1}{c}{ Bueno NB, et al $(2013)^{10}$} \\
\hline Title & $\begin{array}{l}\text { Very-low-carbohydrate ketogenic diet vs low-fat diet for long-term weight loss: a } \\
\text { meta-analysis of randomised controlled trials }\end{array}$ \\
$\begin{array}{l}\text { PICO (Patient, intervention, } \\
\text { comparison, outcome) }\end{array}$ & $\begin{array}{l}\text { PICO used during searching strategy was as follows: } \\
\text { P: patients with BMI }>27.5 \mathrm{~kg} / \mathrm{m}^{2} ;\end{array}$ \\
& $\begin{array}{l}\text { I: ketogenic diet; } \\
\text { C: low-fat diet; }\end{array}$ \\
& $\begin{array}{l}\text { O: weight loss during the last } 12 \text { months } \\
\text { Articles were searched through MEDLINE, CENTRAL, Science Direct, Scopus, }\end{array}$ \\
Literature searching & $\begin{array}{l}\text { LILACS, SciELO and ClinicalTrials.gov using key words: ketogenic diet, weight } \\
\text { loss, and cardiovascular risk factors. }\end{array}$ \\
& Yes, all relevant studies were included; studies which met the PICO criteria and \\
Include all relevant studies & RCTs were included in the analyses. \\
Validity assessment on each & Yes, validity assessment was done on each study \\
study & Yes, the results were consistent on each study \\
Result consistency in each & \\
study & 1 (a meta-analysis from RCTs) \\
Level of Evidence &
\end{tabular}




\section{Importance}

Assessment of the study importance was not done using the $2 \times 2$ table since the outcomes were numerical variables. Therefore, the results of each study were assessed based on the primary and secondary outcomes, if available. Table 5 shows the critical appraisal of the importance of each study.

Table 5. Critical appraisal of the importance aspect of each study

\begin{tabular}{|c|c|}
\hline Study & Results \\
\hline $\begin{array}{l}\text { Wycherley TP, et al } \\
(2010)^{9}\end{array}$ & $\begin{array}{l}\text { Weight loss was observed during the study period (week-0 to week-52), i.e. a reduction of } 14.9 \pm \\
2.1 \mathrm{~kg} \text { in the ketogenic diet group and } 11.5 \pm 1.5 \mathrm{~kg} \text { in the low-fat diet. The difference of weight } \\
\text { loss was not significant between both groups }(p=0.20) \text {. Meanwhile, BMI reduction was } 5.3 \pm 0.7 \\
\left.\mathrm{~kg} / \mathrm{m}^{2} \text { in the ketogenic diet group and } 3.9 \pm 0.5 \mathrm{~kg} / \mathrm{m}^{2} \text { in the low-fat diet group ( } p=0.14\right) \text {. } \\
\text { The secondary outcome was the brachial artery flow-mediated dilatation (FMD), which was } \\
\text { significantly different between both groups. The FMD reduction was } 2.1 \pm 0.6 \% \text { in the ketogenic } \\
\text { diet group and } 0.3 \pm 0.6 \% \text { in the low-fat diet group }(p=0.045) \text {. This showed a higher risk of } \\
\text { endothelial damage in the ketogenic diet group. }\end{array}$ \\
\hline $\begin{array}{l}\text { Bueno NB, et al } \\
(2013)^{10}\end{array}$ & $\begin{array}{l}13 \text { studies were included in the meta-analysis; } 9 \text { studies were done in } 12 \text { months and the other } 4 \\
\text { studies were completed in } 24 \text { months. } \\
\text { Based on this meta-analysis, weight loss was significantly higher in the ketogenic diet group with } \\
\text { weighted mean difference (WMD) of }-0.91(95 \% \mathrm{CI}:-1.65,-0.17) \mathrm{kg}, p=0.02 ; \mathrm{I}^{2}=0 \%, p=0.47 \text {. The } \\
\text { result was consistent across all subgroup analyses, except for the subgroups with } 24 \text { months of } \\
\text { follow-up. } \\
\text { The secondary outcome was low density lipoprotein cholesterol (LDL-C) levels. Among } 12 \text { studies, } \\
\text { which included a total of } 1255 \text { patients, a significantly greater increase of LDL-C levels was } \\
\text { observed in the ketogenic diet compared to low-fat diet group (WMD } 0.12 ; 95 \% \mathrm{CI}: 0.04,0.2 \\
\left.\text { mmol/L, } p=0.002 ; \mathrm{I}^{2}=0 \%, p=0.7\right) \text {. }\end{array}$ \\
\hline
\end{tabular}

\section{Applicability}

Table 6 shows critical appraisal on the applicability of both studies.

Table 6. Critical appraisal on the applicability of both studies

\begin{tabular}{|c|c|c|}
\hline $\begin{array}{l}\text { Parameter of } \\
\text { Applicability }\end{array}$ & Wycherley TP, et al $(2010)^{9}$ & Bueno NB , et al $(2013)^{10}$ \\
\hline
\end{tabular}

\section{Resemblance of the} study subjects with the case

Agreement to the value and preference in the community Feasibility of the therapy in the setting of daily clinical practice
Subjects were males or females, age 24-64 years old, with BMI of $26-43 \mathrm{~kg} / \mathrm{m}^{2}$ (Asian Pacific criteria of obesity). Each subject also had at least one risk factor of metabolic syndrome, no history of organ dysfunction or malignancy, was not pregnant and had no smoking habit.

This study was relevant to the case illustration.

Doubtful. Since ketogenic diet might not be appropriate for Indonesian's culture, therefore adjustment for ketogenic diet is needed with Indonesian's local food availability.

Probably. Professional consultation is required before undergoing ketogenic diet, especially with comorbid diseases.
Studies included in the meta-analysis had inclusion criteria that corresponded with PICO.

However, the characteristics of the study subjects were not further detailed. 
A summary of the results of critically appraised

RCT and meta-analysis is given in Table 7.

Table 7. Summary of results from both studies

\begin{tabular}{llll}
\hline \multicolumn{1}{c}{ Author } & End-point & Result & Conclusion \\
\hline Wycherley & Subject's weight loss, & Weight loss in subjects receiving & Body weight reduction was \\
TP, et al & calculated from the & ketogenic diet vs low-fat diets & higher in the ketogenic diet \\
$(2010)^{9}$ & beginning of study (week 0) & were $14.9 \pm 2.1 \mathrm{~kg}$ vs $11.5 \pm 1.5$ & group yet not statistically \\
& to week 52. In addition, the & $\mathrm{kg}$, respectively $(p=0.20)$. & significant. \\
& cardiovascular risk was also & Additionally, the FMD reduction & However, FMD reduction \\
& counted. & was $2.1 \pm 0.6 \%$ vs. 0.3 $+0.6 \%$, & was significantly higher in \\
& & respectively $(p=0.045)$. & the ketogenic diet group, \\
& & & which suggested higher \\
& & & cardiovascular risk.
\end{tabular}

$\begin{array}{ll}\text { Bueno NB, } & \text { Body weight changes and } \\ \text { et al }(2013)^{10} & \text { indicator of cardiovascular } \\ & \text { risk among various RCTs } \\ & \text { involving ketogenic diet } \\ & \text { intervention. }\end{array}$

From all of the 13 studies included, weight loss was ignificantly higher in subjects assigned to ketogenic diet compared to low-fat diet group (WMD -0.91 (95\% CI 1.65-0.17) $\mathrm{kg}, p=0.02, \mathrm{I}^{2}=0 \%$ ). In addition, there was also an increased LDL$\mathrm{C}$ levels in 12 studies (WMD 0.12 ; 95\% CI: 0.04-0.2; $p=0.002$; $\left.\mathrm{I}^{2}=0 \%\right)$.

\author{
There was a significantly \\ greater weight loss in the \\ ketogenic diet group. The \\ results also showed \\ homogeneity. \\ Secondary outcome \\ assessment showed a \\ homogenous result, i.e. \\ significantly higher \\ increased of LDL-C levels \\ in the ketogenic diet group.
}

\section{Discussion}

After critically assessed the study by Wycherley TP et al, ${ }^{9}$ a potential drawback was observed in the validity aspect of the study due to high number of drop out cases, i.e. 69 drop outs of the 118 subjects. Consequently, the analysis could only be done perprotocol. However, since it was difficult to lower the drop out number in this kind of study, we decided to continue critical appraisal for the importance and applicability aspects. In the importance aspect, the results showed that body weight reduction was greater in the ketogenic diet group compared to the low-fat diet group. However, statistical analysis failed to reach significance and thereby making it inapplicable for generalization to wider populations.

Regarding the applicability, the study result is applicable to patients with similar condition. However, it should be noted that there was a secondary outcome showing that subjects treated with ketogenic diet experience significantly greater FMD reduction $(2.1 \% \pm 0.6 \%$ vs. $0.3 \pm 0.6 \%)$ implying a greater risk of cardiovascular event. It has been documented that $1 \%$ FMD reduction can increase the risk of cardiovascular event to $13 \%$. Therefore, based on the results of this study, ketogenic diet treatment for 12 months can increase the risk of cardiovascular event by approximately $26 \%{ }^{9}$

Critical appraisal done to the meta-analysis by Bueno NB, et al $^{10}$ showed a good validity assessment in terms of PICO strategy, study validity and consistency of the results. In the importance aspect, a significant result was shown by the higher reduction of body weight in the ketogenic diet group (WMD $-0.91 \mathrm{~kg} ; 95 \% \mathrm{CI}$ : $1.65,-0.17 ; p=0.02$ ) with good homogeneity, as shown by the $\mathrm{I}^{2}=0 \%$. Assessment on the applicability aspect also found that the result from this meta-analysis could be applied to the case. On the other hand, the secondary outcome showed higher LDL-C levels in the ketogenic diet group (WMD 0.12; 95\% CI: 0.04, 0.2; $p=0.002 ; \mathrm{I}^{2}=0 \%$ ), indicating a statistical significance and homogenous results. ${ }^{10}$ 
Based on the critical assessment of both studies, ketogenic diet showed a long-term benefit on weight loss, which is better or similar to the low-fat diet. In support of this finding, a review by Paoli et $a l^{12}$ concluded that ketogenic diet had a weight loss effect and was effective in a short period of time to induce weight loss. The mechanisms by which ketogenic diet may reduce body weight include a reduction in appetite by reducing insulin production and by affecting body metabolism that maintain muscle mass and reducing much of the fat mass. ${ }^{6,11,12}$

On the other hand, the secondary outcome suggested that ketogenic diet might increase the risk of cardiovascular event. This finding was supported by the reduction of FMD values in the trial by Wycherley et $a l^{9}$ and increased LDL-C levels in the meta-analysis by Bueno et al. Increased LDL-C levels by ketogenic diet is associated with the high consumption of saturated fat. A study by Chiu et $a l^{13}$ stated that high consumption of high saturated fat would increase LDL-C levels and the risk of cardiovascular disease. In term of FMD reduction by ketogenic diet, another study by Schwingshackl and Hoffmann ${ }^{14}$ has shown a consistent finding. Moreover, a study by Jonavoskli et $a l^{15}$ also stated that a low-carbohydrate diet of $<5 \%$ might reduce FMD. However, a short-term trial by Volek et $a l^{16}$ showed an contrasting result; they found that lowcarbohydrate diet was better in maintaining the FMD. Therefore, further studies are needed to address this issue.

Based on these two critically appraised articles, it can be concluded that ketogenic diet intervention showed a good efficacy in weight loss, which include the short-term $(<3$ months) or longterm (12 to 24 months) effects. However, aside from the desirable body weight loss, ketogenic diet poses a substantially increased risk of cardiovascular event. Therefore, ketogenic diet cannot be recommended as a choice of weight-loss therapy for patients with high risk of cardiovascular disease. Further studies are needed to evaluate the effect and long-term safety of ketogenic diet on cardiovascular risk.

\section{Conflict of Interest}

Authors declared no conflict of interest regarding this study.

\section{Open Access}

This article is distributed under the terms of the Creative Commons Attribution 4.0 International Liscence

(http://creativecommons.org/licenses/by/4.0/), which permits unrestricted use, distribution, and reproduction in any medium, provided you give appropriate credit to the original author(s) and the source, provide a link to the Creative Commons license, and indicate if changes were

\section{Acknowledgement}

The authors would like to acknowledge the magister of clinical nutrition study program in Department of Clinical Nutrition of Universitas Indonesia for helping with this paper.

\section{References}

1. Mitchell N, Catenacci V, Wyatt HR, Hill JO. Obesity: overview of an epidemic. The Psychiatric clinics of North America 2011; 34(4): 717-732.

2. WHO Western Pacific Region. The Asia Pacific perspective: redefining obesity and its treatment. Australia: Health Communications; 2000.

3. Badan Penelitian dan Pengembangan Kesehatan. Riset Kesehatan Dasar 2013. Jakarta: Kementerian Kesehatan RI; 2013.

4. Segula D. Complications of obesity in adults: A short review of the literature. Malawi Medical Journal 2014;26(1):20-24.

5. Caterson ID. Medical management of obesity and its complication. Ann Acad Med Singapore 2009; 38(1): 22-7.

6. Perez-Guisado J. Ketogenic diet and weight loss: basis and effectiveness. Arch LatinoamNutr 2008; 58(2): 126-31.

7. Paoli A. Ketogenic Diet for Obesity: Friend or Foe? International Journal of Environmental Research and Public Health 2014;11(2):2092-2107.

8. Paoli A, Bosco G, Camporesi EM, Mangar D. Ketosis, ketogenic diet and food intake control: a complex relationship. Frontiers in Psychology 2015; 6: 27.

9. Wycherley TP, Brinkworth GD, Keogh JB, Noakes M, Buckley JD, Clifton PM. Long-term effect of weight loss with a very low carbohydrate and low fat diet on vascular function in overweight and obese patients. $J$ Intern Med 2010; 267(5):452-61.

10. Bueno NB, Viera de Melo IS, Lima de Oliveira S, Ataide TR. Very-low-carbohydrate ketogenic diet v. low-fat diet 
for long term weight loss: a meta-analysis of randomised controlled trials. Br J Nutr 2013; 110(7): 1178-87.

11. Dashti HM, Mathew TC, Hussein T, et al. Long-term effects of a ketogenic diet in obese patients. Experimental \& Clinical Cardiology 2004;9(3):200-205.

12. Paoli A, Rubini A, Volek JS, Grimaldi KA. Beyond weight loss: a review of the therapeutic uses of very-lowcarbohydrate (ketogenic) diets. European Journal of Clinical Nutrition 2013;67(8):789-796.

13. Chiu S, Williams PT, Krauss RM. Effects of a very high saturated fat diet on LDL particles in adults with atherogenic dyslipidemia: A randomized controlled trial. PLoS

ONE 12(2):e0170664.doi:10.1371/journal.pone.0170664.

14. Schwingshackl L, Hoffmann G. Low-carbohydrate diets impair flow-mediated dilatation: evidence from a systematic review and meta-analysis. Br J Nutr 2013; 110(5): 969-70.

15. Jovanovski E, Zurbau A, Vuksan V. Carbohydrates and Endothelial Function: Is a Low-Carbohydrate Diet or a Low-Glycemic Index Diet Favourable for Vascular Health? Clinical Nutrition Research 2015;4(2):69-75.
16. Volek JS, Ballard KD, Silvestre R, Judelson DA, Quann $\mathrm{EE}$, Forscythe CE, et al. Effects of dietary carbohydrate restriction versus low-fat diet on flow-mediated dilatation. Metabolism 2009; 58(12): 1769-77. 